\title{
Probabilistic Seismic Hazard Assessment for Taiwan
}

\author{
Yu-Ju Wang ${ }^{1,2, *}$, Chung-Han Chan ${ }^{3}$, Ya-Ting Lee ${ }^{1}$, Kuo-Fong Ma ${ }^{1}$, J. Bruce H. Shyu ${ }^{4}$, Ruey-Juin Rau ${ }^{5}$, \\ and Chin-Tung Cheng ${ }^{6}$ \\ ${ }^{1}$ Department of Earth Sciences, National Central University, Taoyuan City, Taiwan, R.O.C. \\ ${ }^{2}$ Institute of Nuclear Energy Research, Atomic Energy Council, Taoyuan City, Taiwan, R.O.C. \\ ${ }^{3}$ Earth Observatory of Singapore, Nanyang Technological University, Singapore \\ ${ }^{4}$ Department of Geosciences, National Taiwan University, Taipei, Taiwan, R.O.C. \\ ${ }^{5}$ Department of Earth Sciences, National Cheng Kung University, Tainan City, Taiwan, R.O.C. \\ ${ }^{6}$ Disaster Prevention Technology Research Center, Sinotech Engineering Consultants Inc., Taipei, Taiwan, R.O.C.
}

Received 31 August 2015, revised 26 April 2016, accepted 3 May 2016

\begin{abstract}
The Taiwan Earthquake Model (TEM) was established to assess the seismic hazard and risk for Taiwan by considering the social and economic impacts of various components from geology, seismology, and engineering. This paper gives the first version of TEM probabilistic seismic hazard analysis for Taiwan in these aspects. We named it TEM PSHA2015. The model adopts the source parameters of 38 seismogenic structures identified by TEM geologists. In addition to specific fault sourcebased categorization, seismic activities are categorized as shallow, subduction intraplate, and subduction interplate events. To evaluate the potential ground-shaking resulting from each seismic source, the corresponding ground-motion prediction equations for crustal and subduction earthquakes are adopted. The highest hazard probability is evaluated to be in Southwestern Taiwan and the Longitudinal Valley of Eastern Taiwan. Among the special municipalities in the highly populated Western Taiwan region, Taichung, Tainan, and New Taipei City are evaluated to have the highest hazard. Tainan has the highest seismic hazard for peak ground acceleration in the model based on TEM fault parameters. In terms of pseudo-spectral acceleration, Tainan has higher hazard over short spectral periods, whereas Taichung has higher hazard over long spectral periods. The analysis indicates the importance of earthquake-resistant designs for low-rise buildings in Tainan and high-rise buildings in Taichung.
\end{abstract}

Key words: PSHA, TEM PSHA2015, Poisson process, Seismic Hazard, Taiwan

Citation: Wang, Y.J., C. H. Chan, Y. T. Lee, K. F. Ma, J. B. H. Shyu, R. J. Rau, and C. T. Cheng, 2016: Probabilistic seismic hazard assessment for Taiwan. Terr. Atmos. Ocean. Sci., 27, 325-340, doi: 10.3319/TAO.2016.05.03.01(TEM)

\section{INTRODUCTION}

Probabilistic seismic hazard analysis (PSHA; Cornell 1968) determines the probability of exceedance (PoE) of various levels of ground motion over a specified period. It serves as a key reference in mitigating seismic risk, developing building code legislation, selecting sites for public and private infrastructure and calculating insurance premiums. Therefore, researchers are currently attempting to develop a reliable system for PSHA at different spatial scales. For example, the National Research Institute for Earth Science and Disaster Prevention of Japan proposed the Japan Seismic Hazard Information Station Map, which presents seismic hazards at a national scale (J-SHIS 2015). Similarly,

\footnotetext{
* Corresponding author

E-mail:wangzu885@gmail.com
}

the Seismic Hazard Harmonization project in Europe developed a probabilistic seismic hazard map for the European region using the latest information on earthquakes, active faults and crustal deformation (SHARE 2013; Woessner et al. 2015). Various multinational research teams were integrated to develop the Global Seismic Hazard Assessment Program and published global seismic hazard maps in 1999 (Giardini et al. 1999). The Global Earthquake Model recently integrated several research institutes and reinsurance enterprises to develop a seismic hazard assessment engine, OpenQuake (Pagani et al. 2014), for evaluating worldwide seismic hazards.

Taiwan is located at the collision boundary of the Philippine Sea plate and Eurasian plate; hence, it experiences frequent earthquakes and a high seismic hazard. Thus, 
obtaining a seismic hazard map for Taiwan is critical. Such maps for Taiwan were first constructed in the $20^{\text {th }}$ century (Tsai et al. 1987; Chang et al. 1988; Loh et al. 1991a, b). Campbell et al. (2002) developed a seismic hazard model for Taiwan that considered active fault sources-including the Chelungpu fault (which ruptured in 1999) - seismicity, and ground-motion information. Cheng (2002) and Cheng et al. $(2007,2015)$ revised the hazard map using a more precise seismogenic source classification and adopted specific attenuation relationships for different sources. These studies provided reliable seismic hazard assessment by deaggregating data variance and also treated parameter uncertainties using logic trees.

Seismogenic structures are principal components for seismic hazard assessment. Shyu et al. (2005) constructed a neotectonic map of Taiwan that identified 11 structural domains including major active faults and blind faults by collecting structural, geodetic, and seismologic evidence. Based on their 2005 study, Shyu et al. (2016) established a new seismogenic source database including 38 seismogenic structures by combining evidence from geological investigations, information from pre-existing databases and data from new analysis. The database provided the latest comprehensive information on faults for future potentially larger earthquakes.

Ground-motion prediction equations (GMPEs), another important component, are to date the most representative equations for evaluating the ground-shaking induced by seismic sources. Using data from the Taiwan Strong Motion Network, Lin and Lee (2008) and Lin (2009) published regional Taiwan GMPEs for crustal and subduction-zone earthquakes, respectively, following the data processing criteria of the Next-Generation Attenuation (NGA) models (Darragh et al. 2004).

Various databases such as those on active faults, GMPEs and earthquake catalogs are currently maintained. Using these updated databases, we assess a new probabilistic seismic hazard model, which is the first version of the Taiwan Earthquake Model (TEM). Based on this model, TEM continually improves Taiwan PSHA following the updated database and considering epistemic uncertainty to provide important information to the public, engineers, and hazard mitigation agencies.

\section{METHODOLOGY}

In the late 1960s Cornell (1968) developed PSHA, which is currently the most widely adopted approach for describing how a hazard is associated with the exposure period. According to this approach, the probability of an earthquake's occurrence, which follows the Poisson process, can be expressed as

$P(n \geq 1, t, v)=1-e^{-v \cdot t}$ where $n$ is the number of earthquakes, and $v$ is the average recurrence interval for an annual frequency of exceedance, which is given by

$v(Y>y *)=\sum_{i=1}^{N s} \dot{N}_{i} \iint P(Y>y * \mid m, r) f_{M_{i}}(m) f_{R_{i}}(r) d m d r$

where $\sum_{i=1}^{N s}$ summaries the total probability of $N s$ earthquakes in a given region, $P(Y>y * \mid m, r)$ is the probability of the ground-motion parameter $Y$ exceeding a level of $y^{*}$ for a specific magnitude $m$ at a distance $r, f_{M_{i}}(m)$ and $f_{R_{i}}(r)$ are the probability density functions for magnitude and distance, respectively, and $\dot{N}_{i}$ is the annual occurrence rate of earthquakes. To describe the behavior of $\dot{N}_{i}$, two earthquake models are considered: the truncated exponential model (Cosentino et al. 1977) and the characteristic earthquake model (Schwartz and Coppersmith 1984).

The truncated exponential model is based on the Gutenberg-Richter law (Gutenberg and Richter 1944), which describes the seismic magnitude-frequency distribution as a power-law behavior with lower- and upper-magnitude cutoffs. The cumulative form of the annual seismic occurrence rate of the truncated exponential model is

$\log (\dot{N})=a-b M$ for $M \leq$ maximal magnitude

where $\dot{N}$ is the rate of earthquakes having a magnitude greater than or equal to $M, a$ is a constant related to the level of seismic activity, and $b$ is the slope of the power law. The truncated model is appropriate for describing the seismic occurrence rate within a region encompassing a complex fault system or an area without identified faults (Youngs and Coppersmith 1985). Therefore, we adopted this model to represent the seismicity rate for the shallow-background areas and intraplate earthquake sources.

According to paleoseismic studies, individual faults tend to repeatedly rupture along the same segments, causing earthquakes with similar magnitudes. They are called characteristic earthquakes. The history of recurrence rates obtained by dating these characteristic events indicates higher seismicity rates of characteristic earthquakes than those obtained by extrapolating the truncated model (Schwartz and Coppersmith 1984; Wesnousky 1994). After considering the geological evidence, Schwartz and Coppersmith (1984) proposed the characteristic earthquake model, which is more appropriate for describing the seismicity rate along a specific fault.

In the previous PSHA model for Taiwan (Cheng 2002; Cheng et al. 2007, 2015), the hazards induced by specific fault sources were assessed using seismicity rates of a band of earthquake magnitudes $\left(\mathrm{M}_{\mathrm{w}} \geq 6.5\right)$ obtained by the characteristic earthquake model (Schwartz and Coppersmith 1984). We considered the seismic hazards induced by 
specific faults with the seismicity rate of the characteristic earthquake in this study instead, which is considered the model most representative of Taiwan. The occurrence rate for characteristic earthquakes was thus estimated with the slip rate $(S)$ and displacement $(D)$ of the fault as follows:

$\dot{N}=\frac{S}{D}$

$S$ and $D$ were obtained using geological, geomorphological, and geophysical data investigated by the TEM geologists. The characteristic earthquake model is applicable to individual faults and fault segments (Youngs and Coppersmith 1985). Thus, in this study, the seismic behaviors of specific faults and interplate sources were described by the characteristic earthquake.

\section{EARTHQUAKE SOURCE MODELS}

We considered three categories of potential seismic sources: (1) shallow-background area sources: the earthquakes that cannot be associated with a specific fault; (2) specific fault sources: the earthquakes that are caused by a particular fault; and (3) subduction-zone sources: the earthquakes that occur in a subduction zone.

\subsection{Shallow-Background Area Sources}

Earthquakes with focal depths of less than $30 \mathrm{~km}$ and whose ruptures cannot be associated with a defined fault system were considered as shallow-background seismic sources. The background sources were divided into 28 subregions (Fig. 1) according to the tectonic framework, neotectonic architecture, Bouguer gravity anomalies, and geological map (Cheng et al. 2015). To analyze the seismic behavior of each area source, a complete seismic catalog is crucial. Chen et al. (2013) analyzed the Taiwan seismic catalog and reported that the complete magnitude of earthquakes was 4.0 for 1973 - 1993 and 3.0 after 1993. Using a catalog considering the complete magnitudes, the annual seismicity rate for each shallow-background seismic source was characterized by the truncated exponential model [Eq. (3)]. A $b$ value describing the relationship between large and small earthquakes was obtained from the shallow-background seismicity with $\mathrm{M}_{\mathrm{w}}$ larger than 3.0 in all of Taiwan (Fig. 2) in order to avoid the lack of data in areas that have low seismicity. The estimated $b$ value, 1.07 , was then used uniformly in the 28 areas to assess the corresponding $a$ value of each area. Table 1 lists the $a$ and $b$ values of the 28 shallow-area sources estimated with the truncated exponential model. In Taiwan's recorded seismicity history, the maximum recorded shallow-background earthquake magnitude was 6.96 , which occurred offshore Southern Taiwan (Fig. 1) on 5 September 1996. Seismicity rates from a lower magnitude limit of 4.0 to an upper mag- nitude limit of 6.96 were considered in the hazard analysis for the shallow-background seismic sources.

To characterize the faulting type of each area source for further evaluating the appropriate ground-motion intensity through GMPEs, we referred to the focal mechanisms of the five largest earthquakes in each area source (Fig. 1). Focal

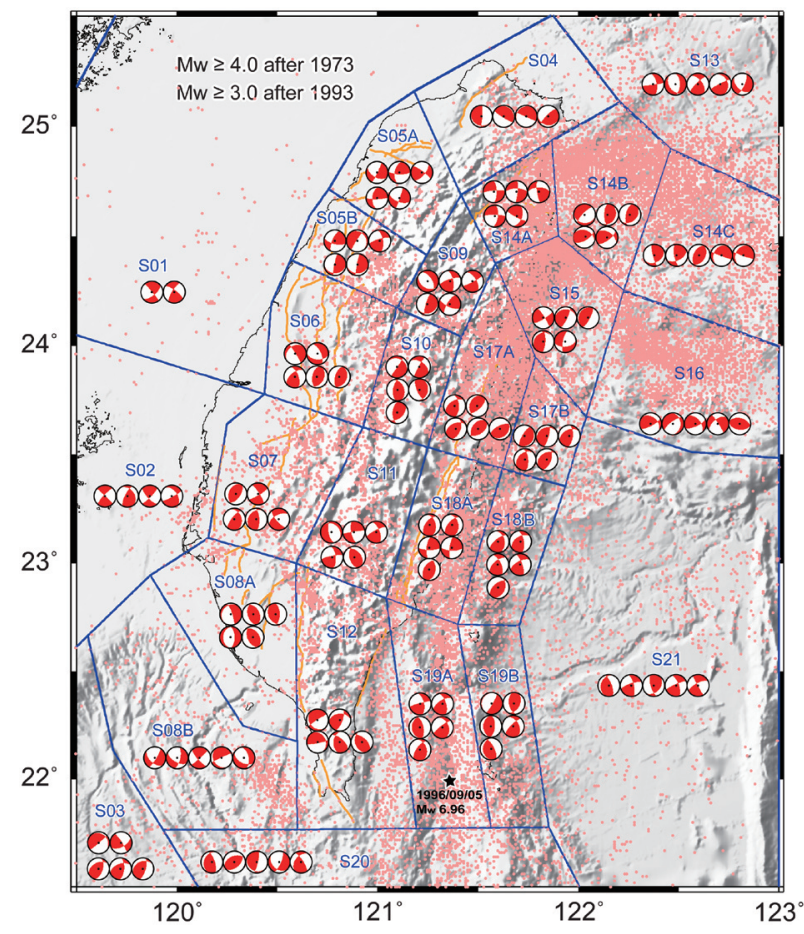

Fig. 1. Distribution of seismicity for estimating the background seismicity rate of 28 partitions. The seismicity cataloged with complete magnitude from 1973 to the end of 2011 is indicated using shallow red dots. Orange lines indicate the 38 seismogenic structures defined by Shyu et al. (2016). Reference focal mechanisms corresponding to the 28 subregions of the area sources are also shown. (Color online only)

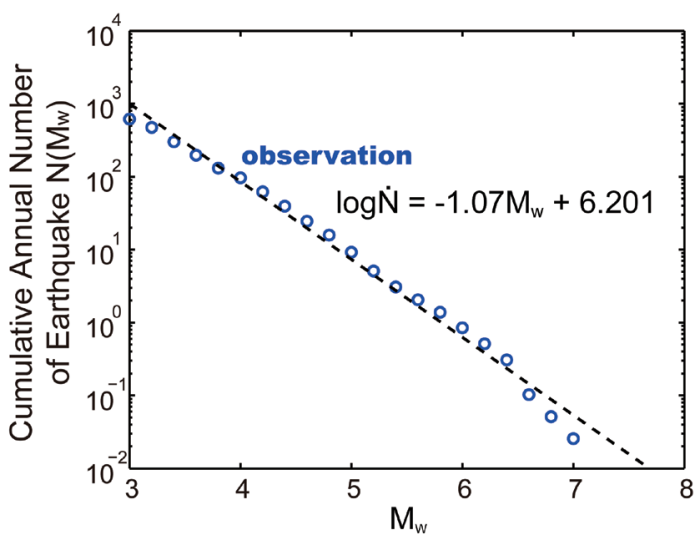

Fig. 2. Regression plot for $b$ value of the shallow-background seismicity with the truncated exponential model. Blue dots indicate the observation data. Theoretical regression line is denoted with the dashed line. The corresponding relationship between annual cumulative earthquake number and the magnitude is also shown. (Color online only) 
Table 1. $a$ and $b$ values of 28 shallow-area sources estimated using the truncated exponential model.

\begin{tabular}{ccc}
\hline Area & $\boldsymbol{a}$-value & $\boldsymbol{b}$-value \\
\hline S01 & $3.69( \pm 0.103)$ & $1.07( \pm 0.053)$ \\
S02 & $4.01( \pm 0.102)$ & $1.07( \pm 0.053)$ \\
S03 & $3.66( \pm 0.117)$ & $1.07( \pm 0.053)$ \\
S04 & $3.17( \pm 0.198)$ & $1.07( \pm 0.053)$ \\
S05A & $3.57( \pm 0.201)$ & $1.07( \pm 0.053)$ \\
S05B & $4.32( \pm 0.052)$ & $1.07( \pm 0.053)$ \\
S06 & $4.63( \pm 0.052)$ & $1.07( \pm 0.053)$ \\
S07 & $4.72( \pm 0.087)$ & $1.07( \pm 0.053)$ \\
S08A & $4.14( \pm 0.061)$ & $1.07( \pm 0.053)$ \\
S08B & $3.74( \pm 0.171)$ & $1.07( \pm 0.053)$ \\
S09 & $3.98( \pm 0.144)$ & $1.07( \pm 0.053)$ \\
S10 & $4.80( \pm 0.172)$ & $1.07( \pm 0.053)$ \\
S11 & $4.63( \pm 0.082)$ & $1.07( \pm 0.053)$ \\
S12 & $4.84( \pm 0.048)$ & $1.07( \pm 0.053)$ \\
S13 & $4.37( \pm 0.136)$ & $1.07( \pm 0.053)$ \\
S14A & $4.34( \pm 0.163)$ & $1.07( \pm 0.053)$ \\
S14B & $4.92( \pm 0.047)$ & $1.07( \pm 0.053)$ \\
S14C & $4.79( \pm 0.123)$ & $1.07( \pm 0.053)$ \\
S15 & $5.33( \pm 0.076)$ & $1.07( \pm 0.053)$ \\
S16 & $5.56( \pm 0.108)$ & $1.07( \pm 0.053)$ \\
S17A & $5.21( \pm 0.053)$ & $1.07( \pm 0.053)$ \\
S17B & $4.42( \pm 0.141)$ & $1.07( \pm 0.053)$ \\
S18A & $4.91( \pm 0.055)$ & $1.07( \pm 0.053)$ \\
S18B & $4.58( \pm 0.080)$ & $1.07( \pm 0.053)$ \\
S19A & $5.16( \pm 0.134)$ & $1.07( \pm 0.053)$ \\
S19B & $4.60( \pm 0.101)$ & $1.07( \pm 0.053)$ \\
S20 & $4.53( \pm 0.110)$ & $1.07( \pm 0.053)$ \\
S21 & $5.12( \pm 0.142)$ & $1.07( \pm 0.053)$ \\
\hline & &
\end{tabular}

mechanisms were determined by the Broadband Array in Taiwan for Seismology, which has routinely estimated the source parameters of earthquakes occurring in Taiwan since 1995. Equal weighting was assumed for the five largest earthquakes (i.e., $20 \%$ for each mechanism).

\subsection{Specific Fault Sources}

In Taiwan several active structure databases have been constructed (e.g., Bonilla 1977; Hsu and Chang 1979; Lee 1999; Shyu et al. 2005; Central Geological Survey 2010). However, some of these databases include only active faults that have apparent surface ruptures and lack structures that produce only tectonic geomorphic features and do not rupture the surface, such as the Chelungpu fault, which is associated with the 1999 Chi-Chi earthquake $\left(M_{w}\right.$ 7.6). These types of faults were absent in the database before 1999 . The 1999 rupture follows a pre-existing topography scarp that could be identified even before the earthquake (Shyu et al. 2005). More detailed fault parameters, such as fault types, fault geometries, slip rates, maximal magnitudes, and recurrence intervals are required for seismic hazard analysis. Shyu et al. (2016) thus combined data from their field surveys and investigations, and reviewed pre-exiting active structure databases and related reports to construct a more comprehensive seismogenic structure database for Taiwan. The database includes faults that have observable ruptures on the surface and also structures that are blind but expressed geomorphically. The geometries of these structures were considered with additional aid from geodetic, geothermal and seismologic data. Possible earthquake magnitudes produced by these structures were estimated using empirical equations (Wells and Coppersmith 1994).

Using the seismogenic source parameters defined by Shyu et al. (2016) (Table 2; Fig. 3a), we assessed seismic hazards induced by characteristic earthquakes of the related fault sources (maximal magnitudes of the ruptures of the faults). The seismic occurrence rate of the characteristic earthquakes was evaluated using Eq. (4). For instance, the ID 7 Hsincheng fault is an important structure in the Hsinchu area and is located in region S05A (Fig. 4). Its fault length is $13 \mathrm{~km}$, dips at $30^{\circ}$, and extends to $12.9 \mathrm{~km}$ (Shyu et al. 2016). The amount of total deformation (displacement), $0.99 \mathrm{~m}$, was evaluated using data from the Digital Elevation Model with $5 \mathrm{~m}$ resolution. Since many of the older terraces in Taiwan are older than the upper limit of the radiocarbon dating method (e.g., Chen 1988; Ota et al. 2002), the age of the structure was estimated according the degree of lateritic development. The lateritic in the Hsincheng fault was categorized as less-developed lateritic soil, and the age was evaluated as $30-150 \mathrm{ka}$ (Shyu et al. 2016). From the aforementioned information, the long-term slip rate and recurrence interval of the Hsincheng fault were obtained as $0.6-3.0 \mathrm{~mm}$ year $^{-1}$ and $330-1650$ years, respectively. We provide a primary version of PSHA with the 38 seismogenic structures in this study. The mean slip rate, $1.8 \mathrm{~mm}_{\text {year }}{ }^{-1}$, was thus used to obtain the rupture occurrence rate for the Hsincheng fault following Eq. (4).

Detailed properties of the 38 seismogenic structures are elaborated by Shyu et al. (2016), who provide comprehensive fault parameter information of each fault for future reference.

\subsection{Subduction-Zone Sources}

Two subduction systems are present around Taiwan, namely the Ryukyu-arc subduction system in the northeastern offshore region and the Manila subduction system in the southern offshore region. According to Cheng et al. (2007), the subduction zones can be divided into 4 interplate (T01A, 
T02A-C) and 12 intraplate (NP1-9, SP1-3) sources (Fig. 3b). The subduction zone geometry was delineated from welllocated seismicity data. T01A is the seismic source on the plate interface of the Ryukyu-arc subduction system. The depth of the fault plane extends from 10 to $45 \mathrm{~km}$. According to historical evidence, the 1920 Hulian earthquake $\left(\mathrm{M}_{\mathrm{w}}\right.$
8.2) was the largest earthquake in this region in the past 100 years. However, the mechanism and focal depth of this earthquake are not yet clear. Kao (1998) suggested that the maximal magnitude of the earthquakes that occurred in $\mathrm{Hu}$ lian is $7.6-7.7$ considering the weekly coupling of the plates and the limited rupture area. We thus considered the mean

Table 2. Adopted source parameters of 38 seismogenic structures identified by TEM

\begin{tabular}{|c|c|c|c|c|c|c|c|c|c|c|c|}
\hline ID & Name & Type & $\begin{array}{c}\text { Rake } \\
\left({ }^{\circ}\right)\end{array}$ & $\begin{array}{c}\text { Length } \\
(\mathbf{k m})\end{array}$ & $\begin{array}{c}\text { Width } \\
(\mathbf{k m})\end{array}$ & $\begin{array}{l}\text { Dip } \\
\left({ }^{\circ}\right)\end{array}$ & $\begin{array}{c}\text { Depth } \\
\text { Max. }(\mathbf{k m})\end{array}$ & $\begin{array}{c}\mathbf{M}_{\mathrm{w}} \\
\text { Max. }\end{array}$ & $\begin{array}{l}\text { Displace- } \\
\text { ment (m) }\end{array}$ & 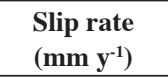 & $\begin{array}{l}\text { Recurrence } \\
\text { interval (y) }\end{array}$ \\
\hline 1 & Shanchiao fault & $\mathrm{N}$ & -90 & 53.40 & 19.84 & 60 & 13.76 & 7.0 & 1.33 & $1.85( \pm 0.76)$ & $511-1220$ \\
\hline 2 & Shuanglienpo structure & $\mathrm{R}$ & 90 & 9.00 & 11.97 & 45 & 5.00 & 6.2 & 0.67 & $0.25( \pm 0.17)$ & $1595-8375$ \\
\hline 3 & Yangmei structure & $\mathrm{R}$ & 90 & 21.70 & 3.46 & 60 & 3.00 & 6.0 & 0.59 & $0.38( \pm 0.26)$ & $921-4538$ \\
\hline 4 & Hukou fault & $\mathrm{R}$ & 90 & 25.80 & 20.00 & 30 & 10.00 & 6.8 & 1.15 & $1.16( \pm 0.84)$ & $575-3593$ \\
\hline 5 & Fengshan river strike-slip structure & SS & 0 & 30.40 & 13.90 & 85 & 13.85 & 6.7 & 0.96 & $3.61( \pm 2.41)$ & $159-800$ \\
\hline 6 & Hsinchu fault & $\mathrm{R}$ & 90 & 12.60 & 14.14 & 45 & 10.00 & 6.4 & 0.81 & $0.70( \pm 0.46)$ & $692-3375$ \\
\hline 7 & Hsincheng fault & $\mathrm{R}$ & 90 & 13.00 & 25.71 & 30 & 12.86 & 6.6 & 0.99 & $1.80( \pm 1.20)$ & $330-1650$ \\
\hline 8 & Hsinchu frontal structure & $\mathrm{R}$ & 90 & 10.40 & 20.00 & 30 & 10.00 & 6.4 & 0.85 & $2.80( \pm 1.86)$ & $182-904$ \\
\hline 9 & Touhuanping structure & SS & 0 & 24.80 & 12.05 & 85 & 12.00 & 6.5 & 0.78 & 0.14 & 5571 \\
\hline 10 & Miaoli frontal structure & $\mathrm{R}$ & 90 & 20.80 & 20.00 & 30 & 10.00 & 6.7 & 1.08 & $3.60( \pm 2.40)$ & $180-900$ \\
\hline 11 & Tunglo structure & $\mathrm{R}$ & 90 & 11.10 & 7.00 & 30 & 3.50 & 6.0 & 0.59 & $1.08( \pm 0.72)$ & $327-1638$ \\
\hline 12 & East Miaoli structure & $\mathrm{R}$ & 90 & 14.10 & 8.00 & 30 & 4.00 & 6.2 & 0.69 & $1.60( \pm 1.06)$ & $259-1277$ \\
\hline 13 & Shihtan fault & $\mathrm{R}$ & 90 & 28.60 & 11.18 & 75 & 10.80 & 6.6 & 0.96 & $1.86( \pm 1.24)$ & $308-1548$ \\
\hline 14 & Sanyi fault & $\mathrm{R}$ & 90 & 27.20 & 34.77 & 15 & 14.85 & 7.0 & 1.44 & $1.86( \pm 1.23)$ & $466-2322$ \\
\hline 15 & Tuntzuchiao fault & SS & 0 & 25.10 & 14.85 & 85 & 14.79 & 6.6 & 0.88 & $1.00( \pm 0.68)$ & $523-2666$ \\
\hline 16 & Changhua fault & $\mathrm{R}$ & 90 & 86.10 & 48.55 & 45 & 12.00 & 7.6 & 2.41 & $3.40( \pm 2.26)$ & $425-2132$ \\
\hline 17 & Chelungpu fault & $\mathrm{R}$ & 90 & 92.00 & 46.36 & 15 & 12.00 & 7.6 & 2.44 & 6.94 & 351 \\
\hline 18 & Tamaopu-Shuangtung fault & $\mathrm{R}$ & 90 & 68.70 & 12.00 & 30 & 6.00 & 7.0 & 1.34 & $2.00( \pm 1.34)$ & $401-2030$ \\
\hline 19 & Chiuchiungkeng fault & $\mathrm{R}$ & 90 & 32.90 & 24.00 & 30 & 12.00 & 6.9 & 1.35 & $7.20( \pm 4.80)$ & $112-562$ \\
\hline 20 & Meishan fault & SS & 0 & 24.00 & 14.75 & 85 & 14.69 & 6.6 & 0.87 & 2.51 & 346 \\
\hline 21 & Chiayi frontal structure & $\mathrm{R}$ & 90 & 44.30 & 46.36 & 15 & 12.00 & 7.3 & 1.86 & $6.49( \pm 4.33)$ & $171-861$ \\
\hline 22 & Muchiliao-Liuchia fault & $\mathrm{R}$ & 90 & 24.90 & 24.00 & 30 & 12.00 & 6.8 & 1.22 & $5.75( \pm 1.35)$ & $171-277$ \\
\hline 23 & Chungchou structure & $\mathrm{R}$ & 90 & 29.70 & 24.00 & 30 & 12.00 & 6.9 & 1.30 & $12.20( \pm 0.60)$ & $101-112$ \\
\hline 24 & Hsinhua fault & SS & 0 & 14.10 & 15.06 & 85 & 15.00 & 6.4 & 0.65 & $2.65( \pm 1.85)$ & $144-812$ \\
\hline 25 & Houchiali fault & $\mathrm{R}$ & 90 & 11.50 & 7.07 & 45 & 5.00 & 6.1 & 0.61 & 7.07 & 86 \\
\hline 26 & Chishan fault & $\mathrm{SS} / \mathrm{R}$ & 45 & 34.80 & 11.18 & 75 & 10.80 & 6.6 & 0.91 & $1.10( \pm 0.36)$ & $623-1246$ \\
\hline 27 & Hsiaokangshan fault & $\mathrm{R}$ & 90 & 9.00 & 14.00 & 30 & 7.00 & 6.2 & 0.70 & $3.30( \pm 2.20)$ & $127-636$ \\
\hline 28 & Kaoping River structure & $\mathrm{SS} / \mathrm{R}$ & 45 & 29.20 & 12.71 & 75 & 12.27 & 6.6 & 0.89 & $0.61( \pm 0.41)$ & $872-4450$ \\
\hline 29 & Chaochou fault & $\mathrm{SS} / \mathrm{R}$ & 45 & 79.60 & 11.50 & 75 & 11.11 & 7.0 & 1.43 & $1.76( \pm 1.17)$ & $488-2423$ \\
\hline 30 & Hengchun fault & $\mathrm{SS} / \mathrm{R}$ & 45 & 37.20 & 15.53 & 75 & 15.00 & 6.8 & 1.14 & $6.15( \pm 0.29)$ & $177-194$ \\
\hline 31 & Hengchun offshore structure & $\mathrm{R}$ & 90 & 14.50 & 8.00 & 30 & 4.00 & 6.2 & 0.69 & $3.65( \pm 1.11)$ & $144-271$ \\
\hline 32 & Milun fault & $\mathrm{SS} / \mathrm{R}$ & 45 & 21.30 & 10.35 & 75 & 10.00 & 6.4 & 0.68 & $10.15( \pm 0.04)$ & $66-67$ \\
\hline 33 & Longitudinal Valley fault & $\mathrm{R} / \mathrm{SS}$ & 45 & 143.10 & 23.79 & 75 & 20.00 & 7.5 & 2.24 & $11.35( \pm 5.75)$ & $130-400$ \\
\hline 34 & Central Range structure & $\mathrm{R}$ & 90 & 85.50 & 28.28 & 45 & 20.00 & 7.4 & 2.02 & $7.28( \pm 1.77)$ & $223-36$ \\
\hline 35 & Luyeh fault & $\mathrm{R}$ & 90 & 17.50 & 6.83 & 45 & 5.00 & 6.2 & 0.69 & $6.34( \pm 0.17)$ & $105-111$ \\
\hline 36 & Taimali coastline structure & $\mathrm{R} / \mathrm{SS}$ & 45 & 42.60 & 10.93 & 75 & 10.55 & 6.7 & 1.11 & $7.32( \pm 1.46)$ & $126-189$ \\
\hline 37 & Northern Ilan structure & $\mathrm{N}$ & -90 & 60.50 & 10.87 & 60 & 9.41 & 6.8 & 1.00 & $3.29( \pm 2.25)$ & $180-961$ \\
\hline 38 & Southern Ilan structure & $\mathrm{N}$ & -90 & 20.60 & 12.99 & 60 & 11.25 & 6.4 & 0.64 & $5.48( \pm 0.64)$ & $104-131$ \\
\hline
\end{tabular}



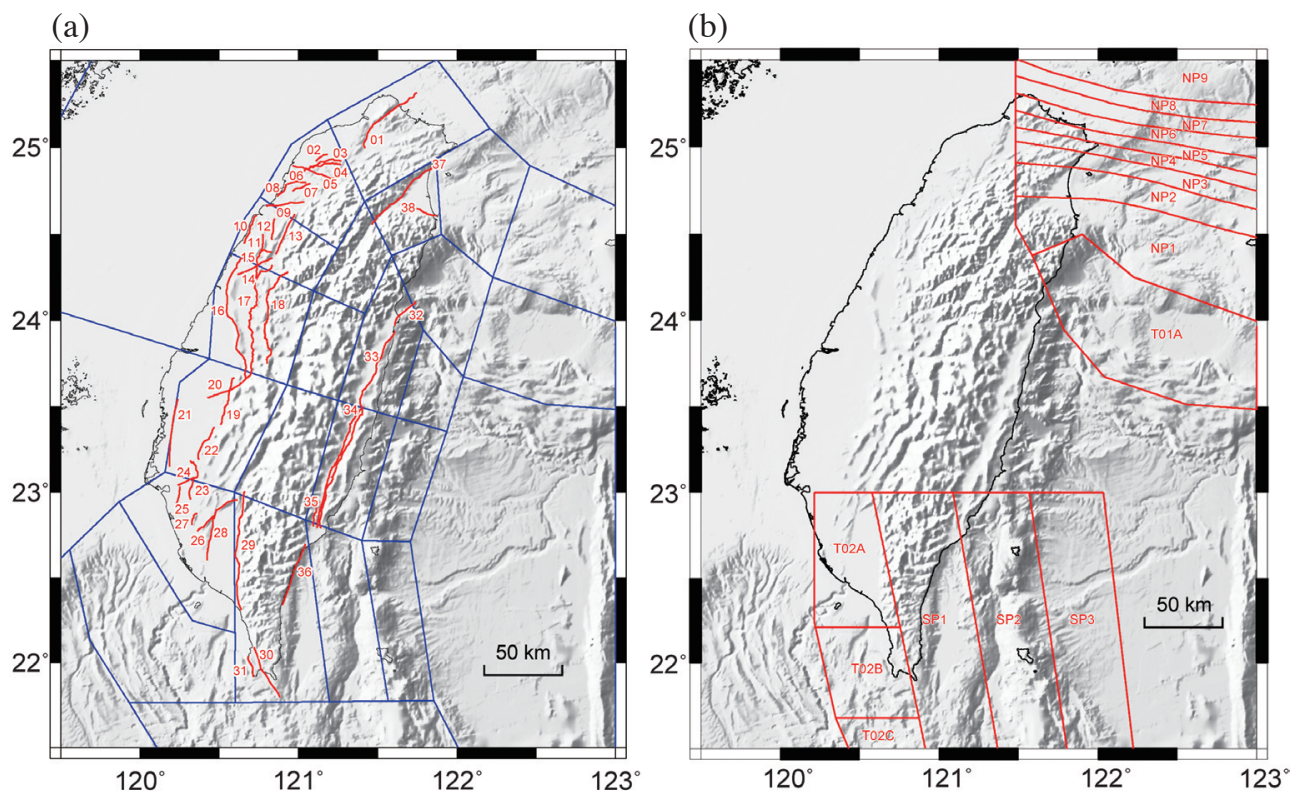

Fig. 3. (a) Distribution of the 38 seismogenic structures defined by Shyu et al. (2016). Blue lines delineate the regions of the 28 area sources. (b) Sub-regions of inter- (T-) and intraplate earthquake sources (SP-, NP-). (Color online only)
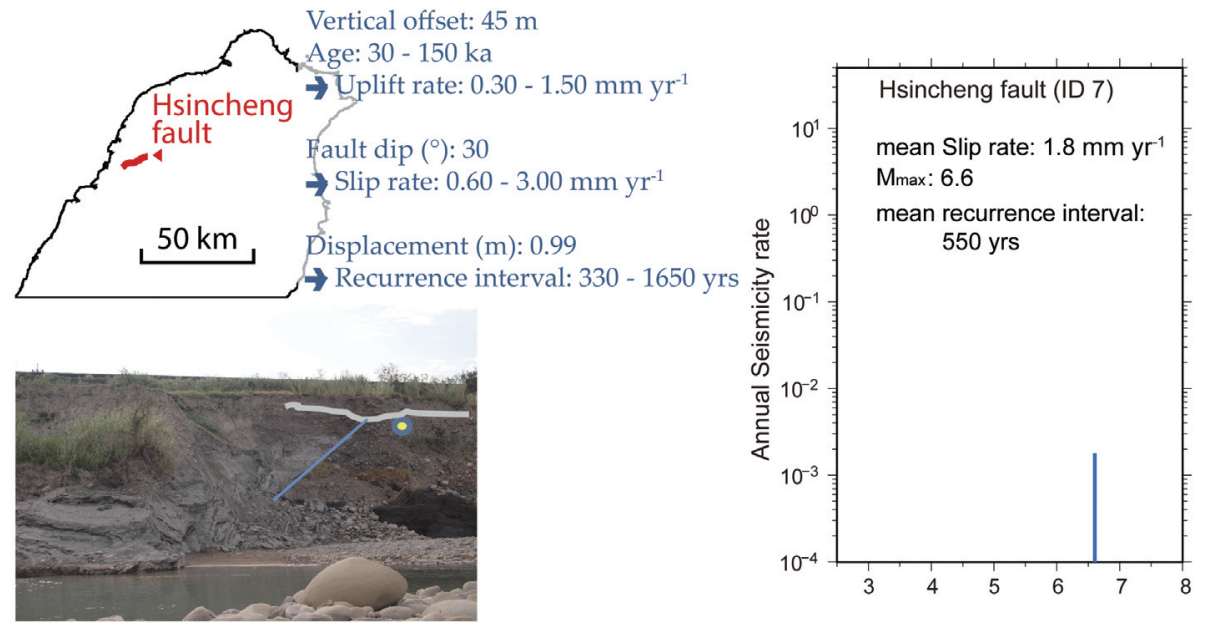

Fig. 4. Example of the seismicity rate of the characteristic earthquake for the Hsincheng fault. The left panel shows the acquisition of parameters for the Hsincheng fault investigated by Shyu et al. (2016). The annual seismicity rate for the characteristic magnitude of the Hsincheng fault is shown in the deep-blue histogram. (Color online only)

value 8.0 as the maximal magnitude along the plate interface of Ryukyu subduction zone. The southern interface region was divided into three segments (T02A-C) according to the turning of the accretionary prism of the Manila subduction zone. A maximal magnitude of 7.5 was considered according to the rupture area of the segments.

The intraplate sources were defined according to the geometry of the subducted plates and iso-depth contours. We referred to the data of global subduction plates (Isacks and Molnar 1971; Fujita and Kanamori 1981; Cheng et al. 2007) for obtaining the maximal magnitudes of the intraplate earthquakes. The corresponding source parameters are listed in Tables 3 and 4 .

The interplate earthquakes generally rupture in a confined megathrust. The seismic occurrence rate of the characteristic earthquake was thus considered in the PSHA. The intraplate earthquakes, which occur within a subduction slab, are generally not attributed to a specific fault system. The annual seismicity rate was evaluated using the truncated exponential model.

\section{GMPES}

GMPEs describe ground-motion intensity relative to 
the earthquake source, seismic wave attenuation, and site effect. Lin and Lee (2008) and Lin (2009) published regional Taiwan GMPEs for crustal and subduction-zone earthquakes, respectively. For crustal earthquakes, the GMPEs used to estimate peak ground acceleration (PGA) and pseudo-spectral acceleration $(\mathrm{Sa})$ are as follows:

$$
\begin{aligned}
\ln (\mathrm{PGA} \text { or } \mathrm{Sa})= & C_{1}+F_{1}+C_{3}(8.5-M)^{2}+ \\
& {\left[C_{4}+C_{5}(M-6.3)\right] \ln \left[\sqrt{R^{2}+\left(e^{H s}\right)^{2}}\right]+} \\
& C_{6} \mathrm{~F}_{\mathrm{NM}}+C_{7} \mathrm{~F}_{\mathrm{RV}}+C_{8} \ln \left(\mathrm{V}_{s} 30 / 1130\right) \\
& \left\{\begin{array}{l}
F_{1}=C_{2}(M-6.3) \text { where } M \leq 6.3 \\
F_{1}=\left(-H C_{5}\right)(M-6.3) \text { where } M>6.3
\end{array}\right.
\end{aligned}
$$

For the subduction-zone earthquakes, the GMPEs are expressed as follows:

$$
\begin{gathered}
\ln (\mathrm{PGA})=C_{1}+C_{2} M+C_{3} \ln \left(R+C_{4} e^{C_{5} M}\right)+ \\
C_{6} H+C_{7} Z_{t}+\ln \varepsilon \\
\ln (\mathrm{Sa})=C_{1}+C_{2} M+C_{3} \ln \left(R+\alpha_{1} e^{\alpha_{2} M}\right)+ \\
\alpha_{3} H+\alpha_{4} Z_{t}+\ln \varepsilon
\end{gathered}
$$

where $C_{1}-C_{8}$ and $\alpha_{1}-\alpha_{4}$ are coefficients of the respective equations; $M$ is the moment magnitude; $R$ is the hypocentral distance $(\mathrm{km})$; $H s$, with a value of 1.5184 , is a saturation term at the closest distance; and $H$ is the focal depth $(\mathrm{km})$. For crustal events, the shear-wave velocity of the sites within $30 \mathrm{~m}$ depth $\left(\mathrm{V}_{\mathrm{s}} 30\right)$ is considered in Eq. (5). However, seismic amplification appears too complex to be related to $\mathrm{V}_{\mathrm{s}}$ in the upmost depths of $30 \mathrm{~m}$ (Castellaro et al. 2008; Abrahamson 2011). Thus, we first considered the PSHA for bedrock sites and adopted $\mathrm{V}_{\mathrm{s}} 30=760 \mathrm{~m} \mathrm{~s}^{-1}$ for all sites. The surface site effects on ground motion will be further assessed with the empirical site-specific amplification factors in the next version of the TEM PSHA model. $\mathrm{F}_{\mathrm{NM}}$ and $\mathrm{F}_{\mathrm{RV}}$ are the variables for the fault type. For normal-faulting earthquakes, $\mathrm{F}_{\mathrm{NM}}=1$ and $\mathrm{F}_{\mathrm{RV}}=0$, and for thrust-faulting earthquakes, $\mathrm{F}_{\mathrm{NM}}=0$ and $\mathrm{F}_{\mathrm{RV}}=1$. In Eqs. (6) and (7), $Z_{t}$ indicates the type of subduction-zone earthquakes $\left(Z_{t}=0\right.$ for interplate earthquakes and 1 for intraplate earthquakes) and $\ln \varepsilon$ is a random error.

These equations were validated by the NGA program (Power et al. 2006). We adopted these equations in our study to evaluate the relative intensity of ground-shaking induced by the various earthquake sources. The ground motion calculation was truncated at two standard deviations.

\section{RESULTS AND DISCUSSION}

Using the source parameters discussed in the preceding section, the probability of seismic hazards in Taiwan
(Fig. 5) and the rupture probabilities for the 38 seismogenic structures (Appendix) were evaluated. The PoEs of $10 \%$ (Fig. 5a) and 2\% (Fig. 5b) in 50 years correspond to the recurrence intervals of 475 and 2475 years, respectively, according to the Poisson process [Eq. (1)]. In addition to the seismic hazard maps, hazard curves, and response spectra of PoE over various exposure times were used to present seismic hazards for six special municipalities (i.e., Taipei, New Taipei City, Taoyuan, Taichung, Tainan, and Kaohsiung) in the highly populated Western Taiwan region (Figs. 6 - 8).

The hazard maps suggest that regions near faults with high maximal magnitudes or short recurrence intervals have high seismic hazards, such as the regions near the Chungchou structure (ID 23), Hengchun fault (ID 30), Milun fault (ID 32), and Longitudinal Valley fault (ID 33) (Fig. 3a). By contrast, the aseismic zones (e.g., the Central Ranges in S09; Fig. 1) and regions with less seismicity (e.g., Northern Taiwan in S04 and S05A) have low seismic hazards. The high-hazard regions identified using the TEM source parameters (Fig. 5) are also shown in the hazard maps generated using the 2010 Central Geological Survey (CGS) source parameters (Cheng et al. 2015, Fig. 9), except the Ilan Plain

Table 3. Source parameters for interplate earthquakes. $\mathbf{M}_{w}$ represents the maximal magnitudes.

\begin{tabular}{cccrcc}
\hline Source & Dip $\left(^{\circ}\right)$ & $\mathbf{M}_{\mathbf{w}}$ & $\begin{array}{c}\text { Length } \\
(\mathbf{k m})\end{array}$ & $\begin{array}{c}\text { Width } \\
(\mathbf{k m})\end{array}$ & $\begin{array}{c}\text { Slip rate } \\
\left(\mathbf{m m} \mathbf{y r}^{-1}\right)\end{array}$ \\
\hline T01A & $20( \pm 2)$ & $8.0( \pm 0.2)$ & 138.69 & 102.3 & $40( \pm 10)$ \\
$\mathrm{T} 02 \mathrm{~A}$ & $24( \pm 2)$ & $7.5( \pm 0.2)$ & 79.12 & 54.1 & $8( \pm 4)$ \\
$\mathrm{T} 02 \mathrm{~B}$ & $24( \pm 2)$ & $7.5( \pm 0.2)$ & 69.06 & 54.1 & $8( \pm 4)$ \\
$\mathrm{T} 02 \mathrm{C}$ & $24( \pm 2)$ & $7.5( \pm 0.2)$ & 81.42 & 54.1 & $8( \pm 4)$ \\
\hline
\end{tabular}

Table 4. Source parameters for intraplate earthquakes. $m_{0}$ and $m_{u}$ represent the minimal and maximal magnitudes, respectively.

\begin{tabular}{ccccc}
\hline \multicolumn{5}{c}{ Intraplate earthquakes } \\
\hline Source & $\boldsymbol{m}_{\mathbf{0}}$ & $\boldsymbol{a}$-value & $\boldsymbol{b}$-value & $\boldsymbol{m}_{\boldsymbol{u}}$ \\
\hline NP1 & 5.0 & 4.20 & 0.91 & $7.7( \pm 0.2)$ \\
NP2 & 5.0 & 3.57 & 0.80 & $7.7( \pm 0.2)$ \\
NP3 & 5.0 & 3.54 & 0.87 & $7.7( \pm 0.2)$ \\
NP4 & 5.0 & 2.68 & 0.73 & $7.8( \pm 0.2)$ \\
NP5 & 5.0 & 3.07 & 0.94 & $7.8( \pm 0.2)$ \\
NP6 & 5.0 & 3.26 & 0.96 & $7.8( \pm 0.2)$ \\
NP7 & 5.0 & 2.46 & 0.73 & $7.8( \pm 0.2)$ \\
NP8 & 5.0 & 3.73 & 1.04 & $7.8( \pm 0.2)$ \\
NP9 & 5.0 & 3.61 & 0.91 & $7.8( \pm 0.2)$ \\
SP1 & 5.0 & 3.07 & 0.76 & $7.7( \pm 0.2)$ \\
SP2 & 5.0 & 3.76 & 0.83 & $7.8( \pm 0.2)$ \\
SP3 & 5.0 & 3.72 & 0.88 & $7.8( \pm 0.2)$ \\
\hline
\end{tabular}



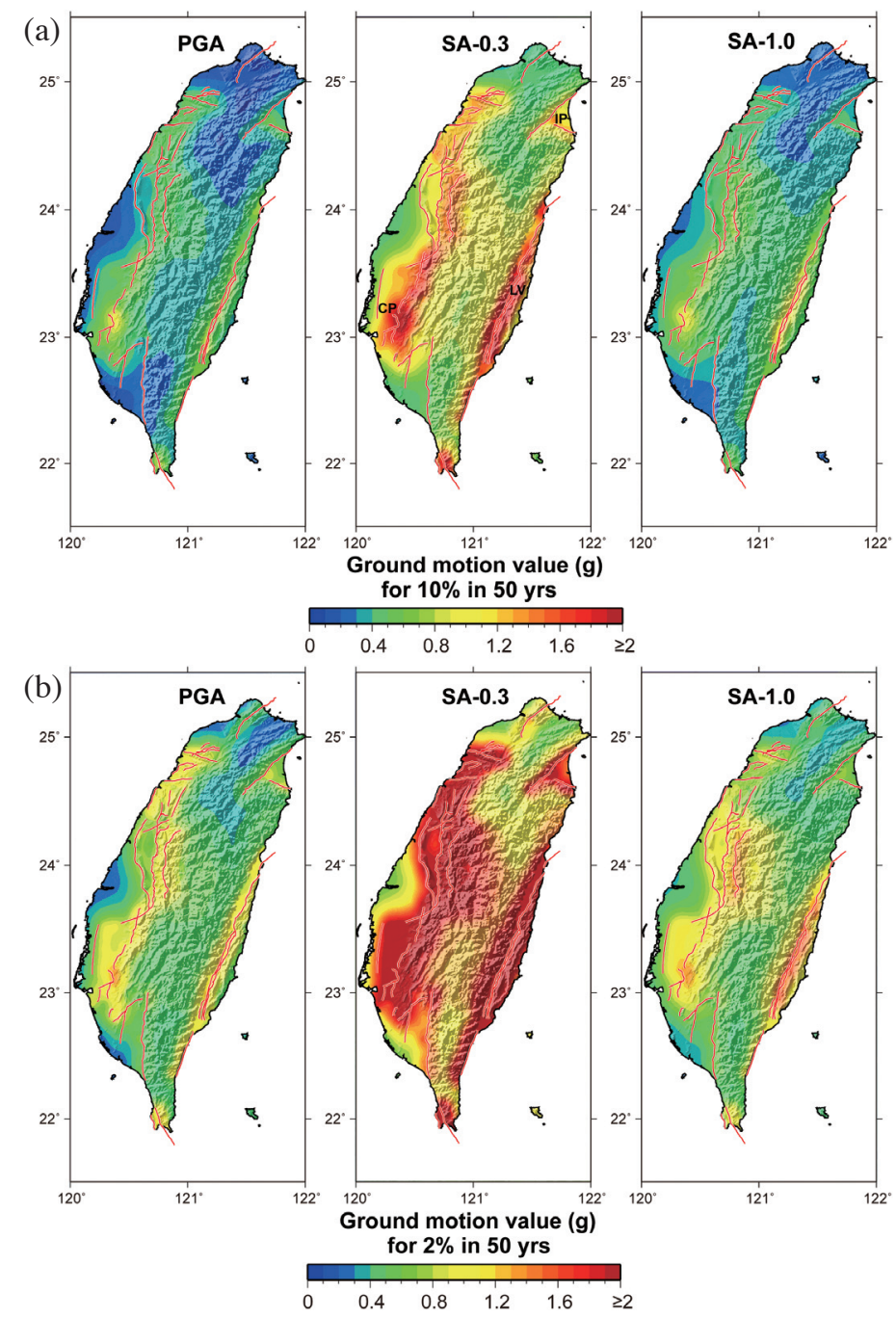

Fig. 5. Hazard maps of PGA, Sa at $0.3 \mathrm{~s}$ (SA-0.3), and Sa at $1.0 \mathrm{~s} \mathrm{(SA-1.0)} \mathrm{for} \mathrm{(a)} 10 \%$ PoE in 50 years (corresponding to a recurrence interval of 475 years) and (b) $2 \%$ PoE in 50 years (corresponding to a recurrence interval of 2475 years) based on the parameters of TEM seismogenic structures. Locations of Chianan Plain, Ilan Plan, and Longitudinal Valley are denoted by CP, IP, and LV, respectively. (Color online only)

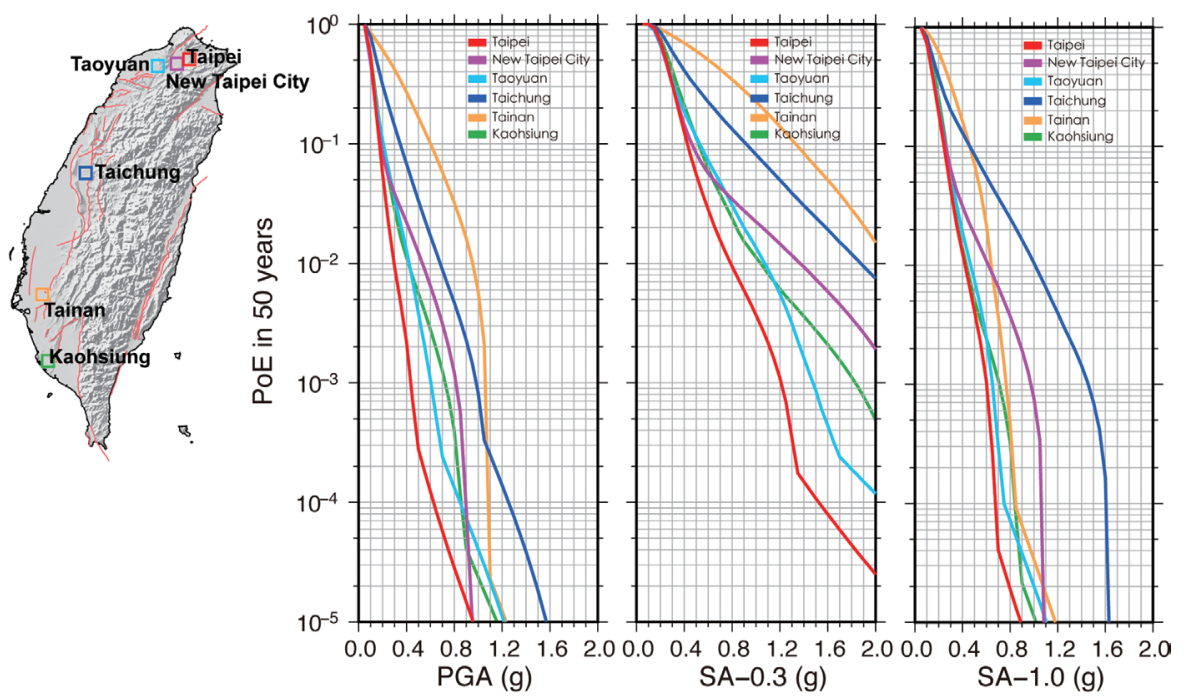

Fig. 6. Hazard curves of PGA (left), Sa at $0.3 \mathrm{~s}$ (middle), and Sa at $1.0 \mathrm{~s}$ (right) with 50 years of exposure time based on TEM seismogenic structure parameters for the six metropolises. (Color online only) 

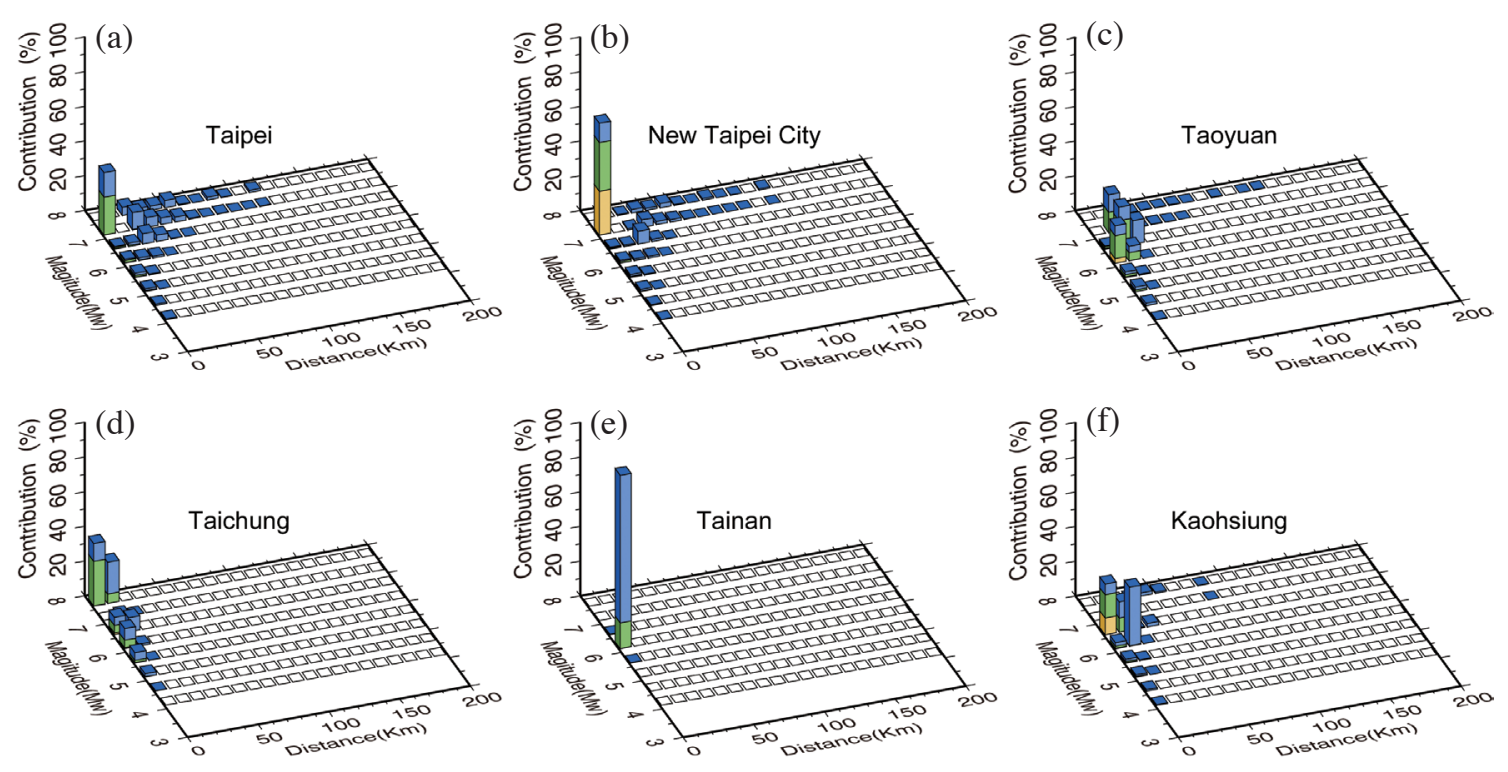

$\square \varepsilon:<-1 \quad \square \varepsilon:-1 \sim 0 \quad \square \varepsilon: 0 \sim 1 \quad \square \varepsilon: 1 \sim 2$

Fig. 7. Deaggregation of PGA with $10 \%$ PoE in 50 years for the six metropolises. (Color online only)

(a)

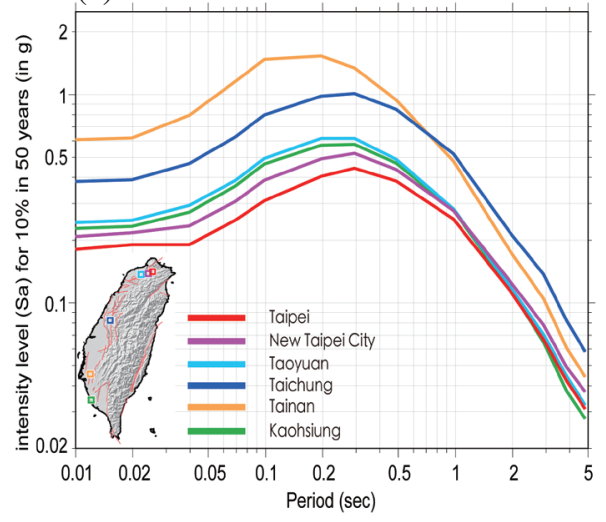

(b)

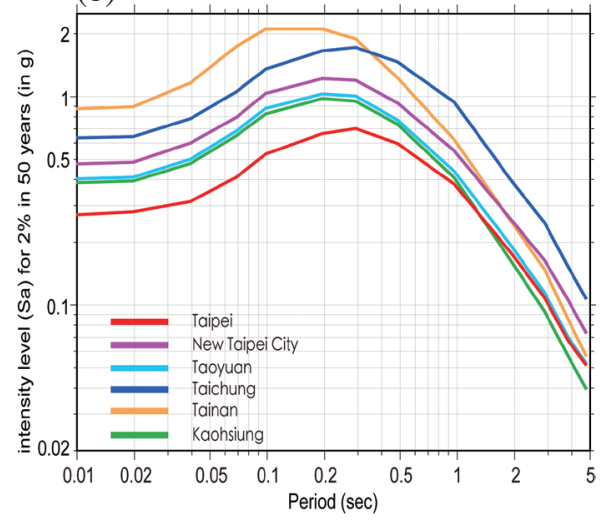

Fig. 8. Response spectra of acceleration for (a) $10 \%$ and (b) $2 \%$ PoEs over 50 years of exposure time for the six metropolises. (Color online only)
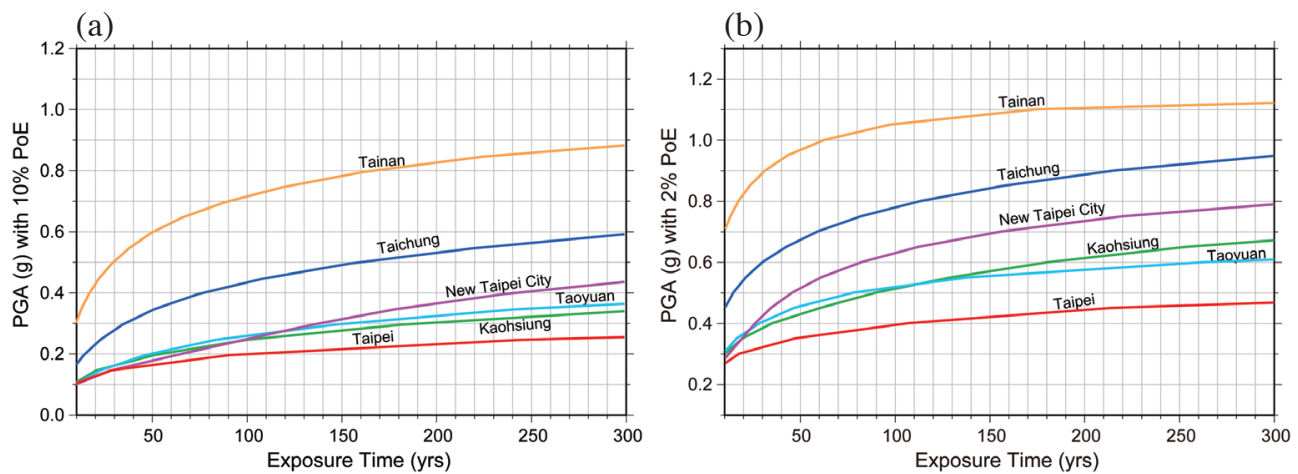

Fig. 9. PGA with (a) $10 \%$ and (b) $2 \%$ PoE over various exposure times for the six metropolitan cities. (Color online only) 
and Hengchun regions, because the Northern Ilan structure (ID 37), Southern Ilan structure (ID 38), and Hengchun offshore structure (ID 31) (Fig. 3a) are not defined in the CGS database.

The hazard maps indicate higher ground motion for $\mathrm{Sa}$ at $0.3 \mathrm{~s}$ (SA-0.3, Fig. 5). For SA-0.3, the expected groundshaking in the Chianan Plain and the Longitudinal Valley is higher than $1.5 \mathrm{~g}$ for a recurrence interval of 475 years. This assessment reflects the high seismic hazard for low-rise (approximately 3 -storied) buildings.

Figure 6 presents the hazard curves for the six metropolitan cities. The hazard curves represent the PoEs as a function of ground-shaking in 50 years for PGA, SA-0.3, and Sa at $1.0 \mathrm{~s}$ (SA-1.0). The curves for SA-0.3 indicate that Tainan has the highest ground-shaking among the six metropolitan cities for the same PoEs. The curves for PGA and SA-1.0 indicate that Tainan has the highest probability of PGA being less than $1.0 \mathrm{~g}$ and SA-1.0 being less than $0.5 \mathrm{~g}$ in 50 years. However, the probability of higher PGA and SA-1.0 is lower than that in Taichung. The low probability of higher PGA and higher SA-1.0 may be related to the smaller earthquakes and effort of short distances contributing to Tainan, as shown in deaggregation analysis (Fig. 7e). The contribution magnitude is mainly around 6 , corresponding to the short fault length of seismogenic structures near Tainan.

In Taipei-the political, economic, and cultural center of Taiwan-all hazard curves in the three periods (Fig. 6) show the lowest PoEs of ground-shaking among the six metropolitan cities. The deaggregation analysis (Fig. 7a) indicates that the earthquake magnitude mainly contributing to hazard is around 7, which is attributable to the Shanchiao fault. The low hazard in Taipei may be related to the long recurrence interval of the Shanchiao fault. However, the long contributing distance (Fig. 7a) implies the significant influence of intraplate earthquakes, which have larger stress drop during their occurrence. The site amplification effect of the Taipei basin has not yet been considered in this study. Thus, close attention to seismic risk mitigation should be given to potential hazards in Taipei, which is highly populated and is the center of crucial political-economic activities.

To discuss the seismic hazards for multistoried buildings we determined the acceleration response spectra for the six metropolitan cities (Fig. 8). For 10\% PoE in 50 years, the estimated Sa of Tainan obtained using the TEM parameters has maximal intensity levels of around $1.5 \mathrm{~g}$ at $0.2 \mathrm{~s}$ (Fig. 8a). For the response spectra estimated with $2 \% \mathrm{PoE}$ in 50 years, the $\mathrm{Sa}$ at a period of less than $0.4 \mathrm{~s}$ is the highest in Tainan; otherwise, the Sa of Taichung is the highest, suggesting that the high-rise buildings in Taichung have a higher hazard. In New Taipei City the high intensity levels for long periods warn about the high seismic risk for the dense high-rise buildings in the city. The outcomes indicate the importance of earthquake-resistant structures for buildings in Tainan, Taichung, and New Taipei City.
Figure 9 illustrates the PGA with 10 and 2\% PoEs for the six metropolitan cities over different exposure times. It provides additional information on earthquake-resistant designs over the period of interest. With increasing exposure time, the PGA at a particular probability increases. For Tainan and Taichung, the cities with the highest hazards, the models indicate that the PGA of Tainan may reach $0.6 \mathrm{~g}$ with $10 \%$ PoE in 50 years and that of Taichung may reach $0.35 \mathrm{~g}$ according to the models based on the TEM parameters (Fig. 9a). The model indicates that the PGA of Tainan may exceed $1.0 \mathrm{~g}$ for exposure times longer than 60 years with $2 \%$ PoE (Fig. 9b).

To understand the relationship between the maximal PGA recorded by the Central Weather Bureau Seismic Network (CWBSN) and the PGA evaluated by the PSHA in this study, we examined the PGA evaluated for a return period of 475 years with the maximal PGA observed by the CWBSN between 1994 and September 2014, an approximately 20 years observation period (Fig. 10). The histograms in green and red represent the maximal PGA recorded at the strong-ground-motion stations and the PGA estimated using the TEM seismogenic structures, respectively. For most regions, the maximal PGA recorded presently is significantly lower than the PGA estimated using the PSHA for the recurrence interval of 475 years. The discrepancy between the recorded and predicted PGA is attributable to the difference in the assessment periods. However, for the region (around $23.5-24.0^{\circ} \mathrm{N}$ ) near the Chelungpu fault, which ruptured during the $1999 \mathrm{M}_{\mathrm{w}}$ 7.6 Chi-Chi earthquake, the maximal recorded PGA is close to the ground-shaking estimated by the PSHA. This indicates that the PSHA did not overestimate the PGA and that the bias introduced by aleatory and epistemic uncertainties was acceptable. To consider the uncertainties in the seismic source parameters, the logic tree analysis would be implemented in the next version of the TEM PSHA.

The present version of TEM PSHA considered an earthquake rupturing on a single-fault-segment. An earthquake rupturing on multi-fault-segments for a potentially larger earthquake is being discussed by TEM geologists. A logical tree considering different scenarios of multi-faultsegments rupture is thus to be deployed in the further TEM PSHA as well.

\section{CONCLUSIONS}

The PSHA based on state-of-the-art earth science knowledge is an effective tool for mitigating seismic hazards during future earthquakes. The TEM team, comprised of geologists, seismologists and engineering seismologists, assess the probabilistic seismic hazards for Taiwan. Using data on the 38 seismogenic structures of the TEM, the first version of the TEM hazard model was obtained. In addition to fault sources, the shallow-background seismicity and 

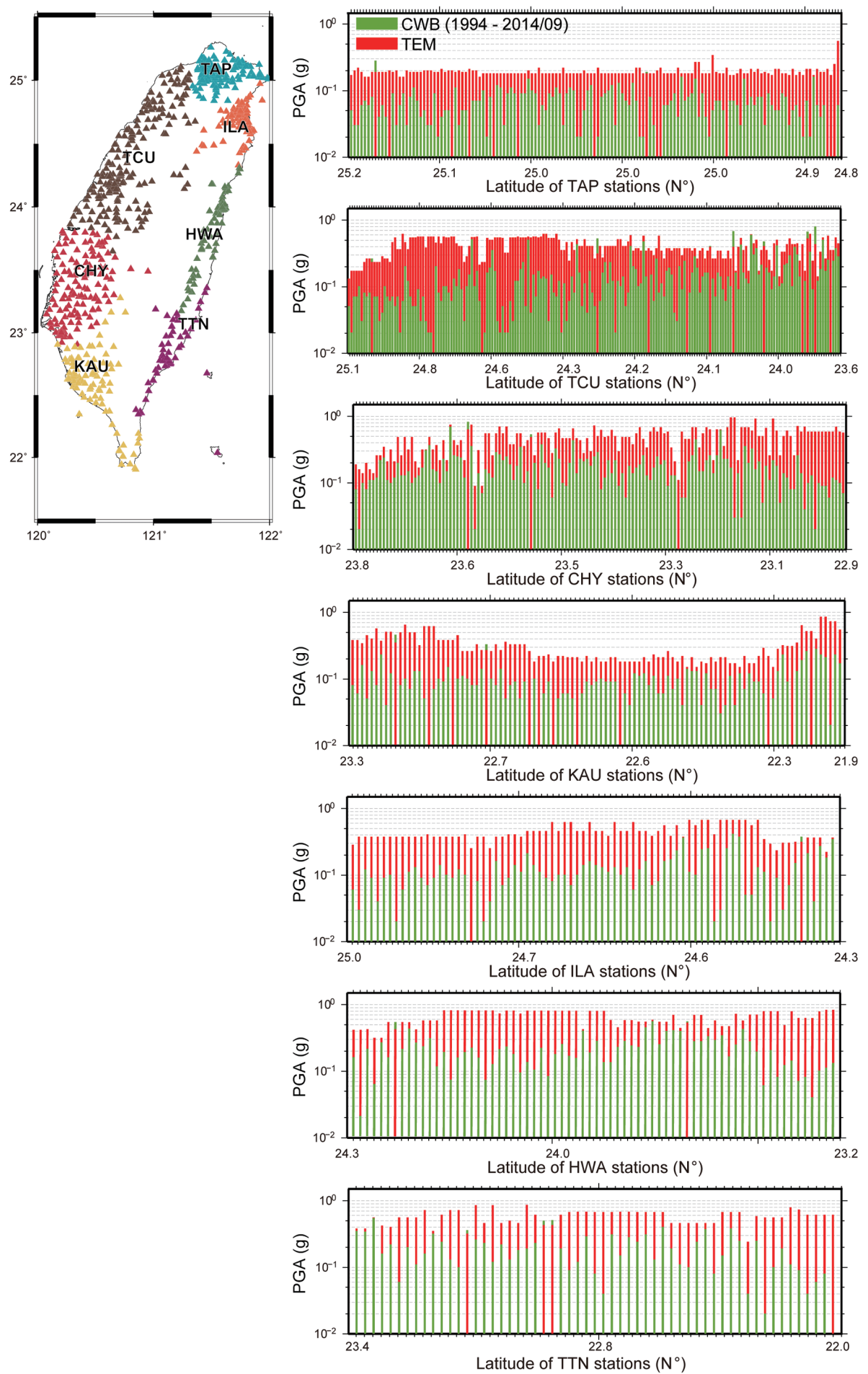

Fig. 10. Comparison of recorded and estimated PGA at all strong-ground-motion stations throughout Taiwan. (Right) Green bars indicate the maximal PGA that has been recorded between 1994 and September 2014 of the CWB instrumental period. Red bars indicate the PGA for a recurrence interval of 475 years estimated using the TEM parameters. The PGA values are classified station-wise. The station takes the name of the region in which the station is located. They are aligned according to the latitude of the stations from north to south. TAP, TCU, CHY, KAU, ILA, HWA, and TTN denote the Taiwan strong-ground-motion stations in Taipei, Taichung, Chiayi, Kaohsiung, Ilan, Hualian, and Taitung areas, respectively (left panel). (Color online only) 
intra- and interplate earthquakes in the subduction zones were considered in the model.

The expected ground-shaking in the Chianan Plain, Hengchun and the Longitudinal Valley is higher than $1.5 \mathrm{~g}$ for $\mathrm{Sa}$ at $0.3 \mathrm{~s}$. The three metropolitan areas with the highest seismic hazards are Tainan, Taichung, and New Taipei City. For $\mathrm{Sa}$ at periods longer than $0.3 \mathrm{~s}$, Taichung has the strongest ground motion. Tainan has higher hazards for short periods but lower hazards for periods longer than $1.0 \mathrm{~s}$, compared with Taichung. The analysis indicates the importance of earthquake-resistant designs for buildings in Tainan, Taichung, and New Taipei City.

Acknowledgements We thank the Global Earthquake Model (GEM) for developing the open source software OpenQuake, using which this study was conducted. In addition, the suggestions and comments from Taiwan Earthquake Model (TEM) committee members helped advance this study. This study was supported by the TEM, which is funded by the National Science Council under grants NSC 102-2119-M006-010 and 104-2119-M-006-007.

\section{REFERENCES}

Abrahamson, N., 2011: Is VS30 an effective parameter for site characterization? Fourth IASPEI/IAEE International Symposium: Effects of Surface Geology on Seismic Motion, 24-26 August 2011, University.

Bonilla, M. G., 1977: Summary of Quaternary faulting and elevation changes in Taiwan. Mem. Geol. Soc. China, 2, 43-56.

Campbell, K. W., P. C. Thenhaus, T. P. Barnhard, and D. B. Hampson, 2002: Seismic hazard model for loss estimation and risk management in Taiwan. Soil Dyn. Earthq. Eng., 22, 743-754, doi: 10.1016/S02677261(02)00095-7. [Link]

Castellaro, S., F. Mulargia, and P. L. Rossi, 2008: VS30: Proxy for seismic amplification? Seismol. Res. Lett., 79, 540-543, doi: 10.1785/gssrl.79.4.540. [Link]

Central Geological Survey, 2010: Active fault map of Taiwan. Available at http://fault.moeacgs.gov.tw/UploadFiles/images/500K/C_activefault(A4)_E.jpg.

Chang, S. Y., C. H. Loh, and S. S. Chen, 1988: Distribution of seismic hazard and risk analysis of buried pipelines in Taiwan. J. Chin. Inst. Eng., 11, 11-23, doi: 10.1080/02533839.1988.9677037. [Link]

Chen, C. H., J. P. Wang, Y. M. Wu, C. H. Chan, and C. H. Chang, 2013: A study of earthquake inter-occurrence times distribution models in Taiwan. Nat. Hazards, 69 , 1335-1350, doi: 10.1007/s1 1069-012-0496-7. [Link]

Chen, Y. G., 1988: C-14 dating and correlation of river terraces along the lower reach of the Tahan-chi, northern Taiwan. Master Thesis, National Taiwan University, Taipei, 88 pp. (in Chinese)
Cheng, C. T., 2002: Uncertainty analysis and deaggregation of seismic hazard in Taiwan. Ph.D. Thesis, Institute of Geophysics, National Central University, Chung-Li, Taiwan, 227 pp. (in Chinese)

Cheng, C. T., S. J. Chiou, C. T. Lee, and Y. B. Tsai, 2007: Study on probabilistic seismic hazard maps of Taiwan after Chi-Chi earthquake. J. GeoEngineering, 2, 19-28.

Cheng, C. T., P. S. Hsieh, P. S. Lin, Y. T. Yen, and C. H. Chan, 2015: Probability seismic hazard mapping of Taiwan. Encyclopedia of Earthquake Engineering, Springer Berlin Heidelberg, 1-25, doi: 10.1007/978-3642-36197-5_100-1. [Link]

Cornell, C. A., 1968: Engineering seismic risk analysis. Bull. Seismol. Soc. Am., 58, 1583-1606.

Cosentino, P., V. Ficarra, and D. Luzio, 1977: Truncated exponential frequency-magnitude relationship in earthquake statistics. Bull. Seismol. Soc. Am., 67, 1615-1623.

Darragh, B., W. Silva, and N. Gregor, 2004: Strong motion record processing for the PEER center. Proceedings of COSMOS Invited Workshop on Strong-Motion Record Processing, Richmond, Calif, USA.

Ellsworth, W. L., M. V. Matthews, R. M. Nadeau, S. P. Nishenko, P. A. Reasenberg, and R. W. Simpson, 1999: A physically-based earthquake recurrence model for estimation of long-term earthquake probabilities. Open-File Report 99-522, U.S. Geological Survey, Reston, VA, 23 pp. Available at http://pubs.usgs.gov/ of/1999/0522/.

Fujita, K. and H. Kanamori, 1981: Double seismic zones and stresses of intermediate depth earthquakes. Geophys. J. Int., 66, 131-156, doi: 10.1111/j.1365-246X.1981. tb05950.x. [Link]

Giardini, D., G. Grünthal, K. M. Shedlock, and P. Zhang, 1999: The GSHAP global seismic hazard map. Ann. Geophys., 42, 1225-1230, doi: 10.4401/ag-3784. [Link]

Gutenberg, B. and C. F. Richter, 1944: Frequency of earthquakes in California. Bull. Seismol. Soc. Am., 34, 185-188.

Hsu, T. L. and H. C. Chang, 1979: Quaternary faulting in Taiwan. Mem. Geol. Soc. China, 3, 155-165.

Isacks, B. and P. Molnar, 1971: Distribution of stresses in the descending lithosphere from a global survey of focalmechanism solutions of mantle earthquakes. Rev. Geophys., 9, 103-174, doi: 10.1029/RG009i001p00103. [Link]

J-SHIS, 2015: Japan Seismic Hazard Information. Available at http://www.j-shis.bosai.go.jp/map/?lang=en.

Kao, H., 1998: Can great earthquakes occur in the southernmost Ryukyu arc-Taiwan region? Terr. Atmos. Ocean. Sci., 9, 487-508.

Lee, C. T., 1999: Neotectonics and active faults in Taiwan. 
Workshop on Disaster Prevention/Management and Green Technology, Foster City, CA, USA, 61-74.

Lin, P. S., 2009: Ground-motion attenuation relationship and path-effect study using Taiwan Data set. Ph.D. Thesis, Institute of Geophysics, National Central University, Chung-Li, Taiwan, 157 pp. (in Chinese)

Lin, P. S. and C. T. Lee, 2008: Ground-motion attenuation relationships for subduction-zone earthquakes in northeastern Taiwan. Bull. Seismol. Soc. Am., 98, 220-240, doi: 10.1785/0120060002. [Link]

Loh, C. H., Y. T. Yeh, W. Y. Jean, and Y. H. Yeh, 1991a: Seismic hazard analysis in Taiwan: Based on PGA and spectral acceleration attenuation formula. J. Eng. Geol., 30, 277-304.

Loh, C. H., Y. T. Yeh, W. Y. Jean, and Y. H. Yeh, 1991b: Seismic hazard analysis in the Taiwan area using a bounded fault-rupture model. Bull. Seismol. Soc. Am., 81, 265-272.

Ota, Y., J. B. H. Shyu, Y. G. Chen, and M. L. Hsieh, 2002: Deformation and age of fluvial terraces south of the Choushui River, central Taiwan, and their tectonic implications. West. Pac. Earth Sci., 2, 251-260.

Pagani, M., D. Monelli, G. Weatherill, L. Danciu, H. Crowley, V. Silva, P. Henshaw, L. Butler, M. Nastasi, L. Panzeri, M. Simionato, and D. Vigano, 2014: OpenQuake Engine: An open hazard (and risk) software for the Global Earthquake Model. Seismol. Res. Lett., 85, 692-702, doi: 10.1785/0220130087. [Link]

Power, M., B. Chiou, N. Abrahamson, and C. Roblee, 2006: The next generation of ground motion attenuation models (NGA) project: An overview. Proceedings, Eighth National Conference on Earthquake Engineering.

Schwartz, D. P. and K. J. Coppersmith, 1984: Fault behavior and characteristic earthquakes: Examples from the Wasatch and San Andreas fault zones. J. Geophys. Res., 89, 5681-5698, doi: 10.1029/JB089iB07p05681. [Link]

SHARE, 2013: European Seismic Hazard Map, Seismic Hazard Harmonization in Europe. Available at http:// www.share-eu.org/node/90.

Shyu, J. B. H., K. Sieh, Y. G. Chen, and C. S. Liu, 2005: Neotectonic architecture of Taiwan and its implications for future large earthquakes. J. Geophys. Res., 110, B08402, doi: 10.1029/2004JB003251. [Link]

Shyu, J. B. H., Y. R. Chuang, Y. L. Chen, Y. R. Lee, and C. T. Cheng, 2016: A new on-land seismogenic structure source database from the Taiwan Earthquake Model (TEM) project for seismic hazard analysis of Taiwan. Terr. Atmos. Ocean. Sci., 27, 311-323, doi: 10.3319/ TAO.2015.11.27.02(TEM). [Link]

Tsai, C. C., C. H. Loh, and Y. T. Yeh, 1987: Analysis of earthquake risk in Taiwan based on seismotectonic zones. Mem. Geol. Soc. China, 9, 413-446.

Wells, D. L. and K. J. Coppersmith, 1994: New empirical relationships among magnitude, rupture length, rupture width, rupture area, and surface displacement. Bull. Seismol. Soc. Am., 84, 974-1002.

Wesnousky, S. G., 1994: The Gutenberg-Richter or characteristic earthquake distribution, which is it? Bull. Seismol. Soc. Am., 84, 1940-1959.

Woessner, J., D. Laurentiu, D. Giardini, H. Crowley, F. Cotton, G. Grünthal, G. Valensise, R. Arvidsson, R. Basili, M. B. Demircioglu, S. Hiemer, C. Meletti, R. W. Musson, A. N. Rovida, K. Sesetyan, M. Stucchi, The SHARE Consortium, 2015: The 2013 European Seismic Hazard Model: Key components and results. Bull. Earthq. Eng., 13, 3553-3596, doi: 10.1007/s10518015-9795-1 [Link]

Youngs, R. R. and K. J. Coppersmith, 1985: Implications of fault slip rates and earthquake recurrence models to probabilistic seismic hazard estimates. Bull. Seismol. Soc. Am., 75, 939-964.

\section{APPENDIX}

Based on the fault parameters of the 38 seismogenic structures identified by the TEM, the rupture probability of each fault in the next 30, 50, and 100 years was evaluated (Figs. A1 - A3). The lapsed time since the last rupture of the fault is a key parameter for obtaining reliable information on earthquake rupture probability with time. Accordingly, we incorporated both excavation data, historical and instrumental earthquake catalogs documented by TEM (http:// tec.earth.sinica.edu.tw/TEM/historic.php? $\mathrm{p}=4$ ) with best-fit Brownian Passage Time (BPT, Ellsworth et al. 1999) mod$\mathrm{el}$, to evaluate the earthquake rupture probabilities of each seismogenic structure. For the seismogenic structures without excavation, historical, or instrumental data, the Poisson model was adopted.

The BPT model was first proposed by Ellsworth et al. (1999) and used in the Working Group on California Earthquake Probabilities (WGCEP) study. The probability density function $(P D F)$ for the distribution can be expressed as

$P D F=\left(\frac{\mu}{2 \pi \alpha^{2} t^{3}}\right)^{1 / 2} \exp \left[-\frac{(t-\mu)^{2}}{2 \alpha^{2} \mu t}\right]$

where $\mu$ is the mean recurrence interval, $t$ is the lapsed time since the last earthquake, and $\alpha$ is the aperiodicity. We assumed that the aperiodicity is the ratio of standard deviation to mean recurrence interval of the recurrence intervals.

The seismogenic structures of ID 13,15, 16, 17, 20, 22, 24,32 , and 33 were estimated with the BPT model, while the others were assessed with the Poisson model. The rupture probabilities for three magnitudes, $\mathrm{M}_{\mathrm{w}} 6.5,6.7$, and 7.0, in the next 30, 50, and 100 years for Northern, Central, Southern, and Eastern Taiwan are shown as well (Figs. A1 - A3). 


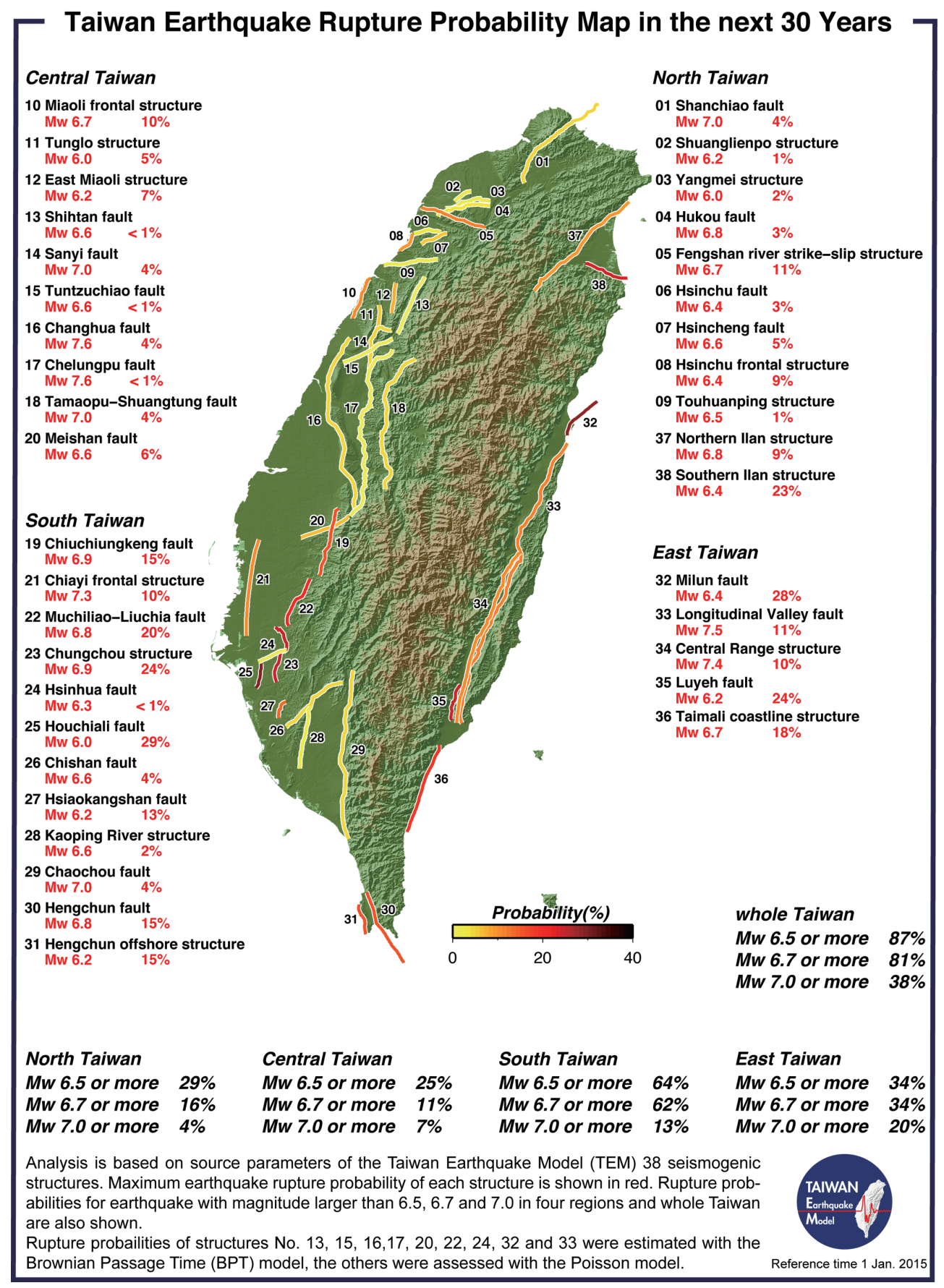

Fig. A1. Rupture probability of Taiwan's 38 seismogenic structures in the next 30 years. (Color online only) 


\section{Taiwan Earthquake Rupture Probability Map in the next 50 Years}

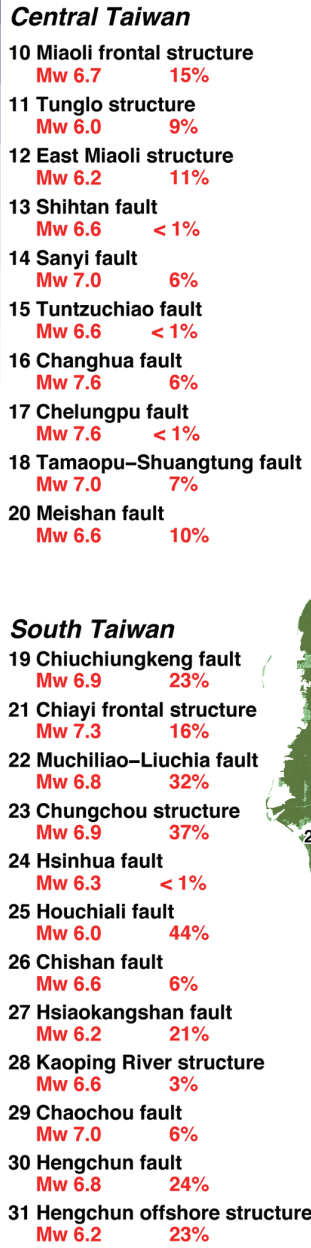

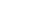

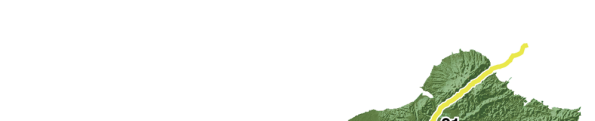

\section{East Taiwan}

Mw 6.5 or more $\quad 50 \%$

Mw 6.7 or more $\quad 50 \%$ Mw 7.0 or more $31 \%$

Analysis is based on source parameters of the Taiwan Earthquake Model (TEM) 38 seismogenic structures. Maximum earthquake rupture probability of each structure is shown in red. Rupture probabilities for earthquake with magnitude larger than $6.5,6.7$ and 7.0 in four regions and whole Taiwan are also shown.

Rupture probailities of structures No. 13, 15, 16,17, 20, 22, 24, 32 and 33 were estimated with the Brownian Passage Time (BPT) model, the others were assessed with the Poisson model.

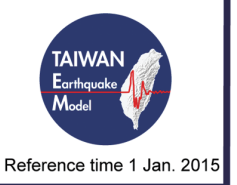

Fig. A2. Rupture probability of Taiwan's 38 seismogenic structures in the next 50 years. (Color online only) 


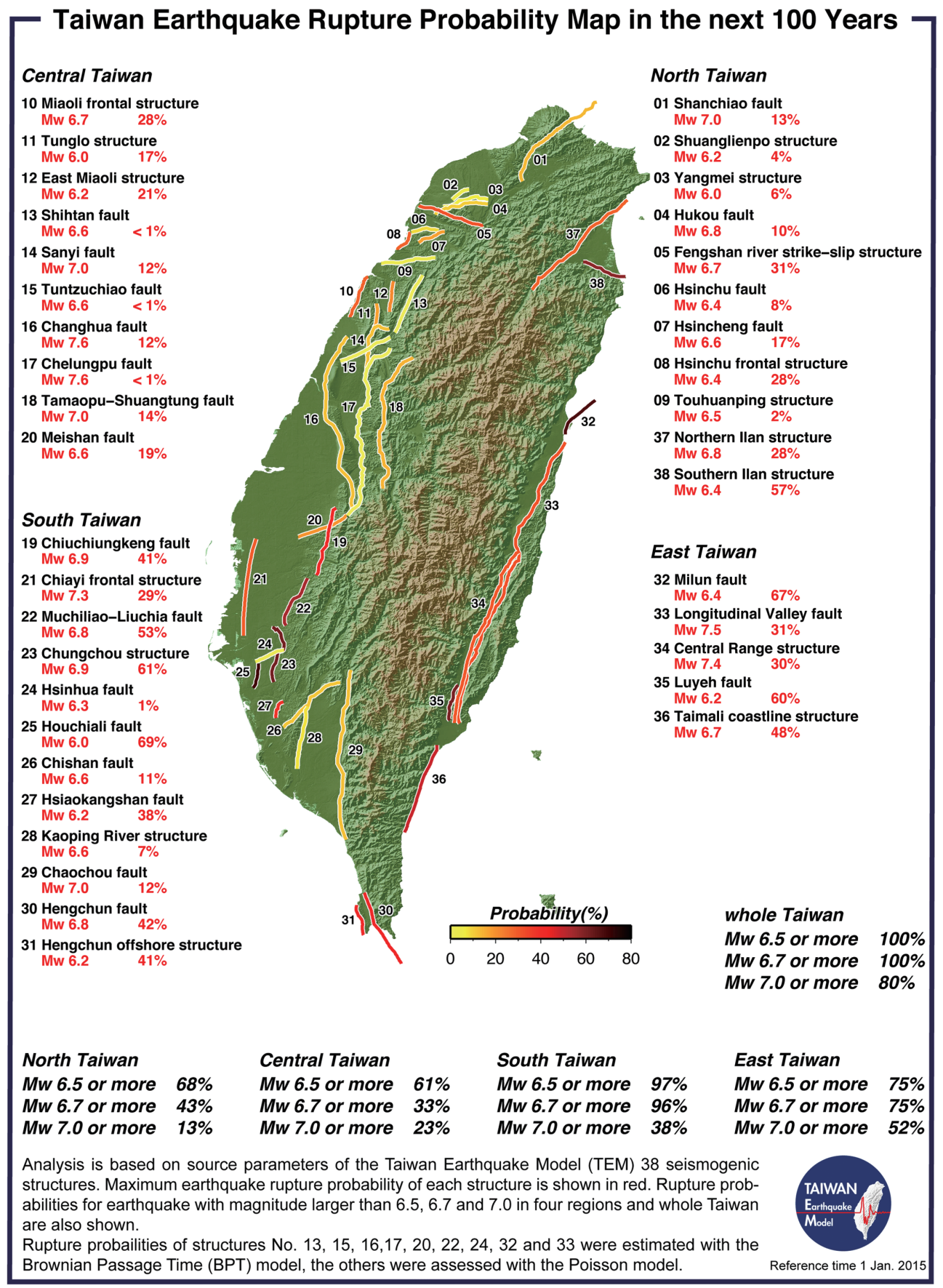

Fig. A3. Rupture probability of Taiwan's 38 seismogenic structures in the next 100 years. (Color online only) 